\title{
SIMULATION AS A TOOL FOR LIFE CYCLE COST ANALYSIS
}

\author{
Khaled Shahata \\ Infrastructure Engineer, UMA Engineering Ltd., \\ Mississauga, Ontario, Canada
}

\author{
Tarek Zayed \\ Assoc. Professor, Dept of Building, Civil, and Env. Eng., \\ Concordia University, Montreal, Quebec, Canada
}

\begin{abstract}
Life cycle cost is an essential approach to decide on alternative rehabilitation strategies for infrastructure systems. Monte Carlo simulation approach is used to develop a stochastic life cycle cost (SLCC) model and methodology in order to compare different rehabilitation scenarios/alternatives for infrastructures, such as water mains. The presented research in this paper identifies several rehabilitation methods for water mains, which are classified into three main categories: repair, renovation, and replacement. The developed model helps academics and practitioners (e.g. municipal engineers) to predict the suitable new installation and/or rehabilitation programs as well as their corresponding costs, thereby, to avoid any unpleasant surprises.
\end{abstract}

\section{INTRODUCTION}

Repair and/or replacement decision of municipal water systems is a major issue that faces most municipalities in Canada and USA. Therefore, the National Research Council of Canada (NRC) has published several publications addressing these decision-making issues for water mains. Most public funding decisions are often made on the basis of initial cost without the consideration of life-cycle costs (Arditi and Messiha, 1999). The concept of life cycle cost can be applied to the whole project and/or part of the project (Hass, 1997). Literature review shows that there are three main methods used in modeling life cycle cost: deterministic, stochastic (probabilistic), and Fuzzy ( $\mathrm{Ka}$ hraman et al. 2002). Most life cycle cost (LCC) models for civil infrastructure assume deterministic behavior of its service life (Hass et al., 1994; Hudson et al., 1997). It is reported that additional research is required to develop better LCC models and tools to quantify the risks, costs, and benefits associated with some civil infrastructures (Farngopol et al., 2001).

In order to take repair and/or replacement decisions for water mains, there are some common decision variables have to be considered such as: (1) type of rehabilitation al- ternative and (2) implementation timing of the pipe (Kleiner et al., 2001). The pipe rehabilitation alternatives include: (1) relining (only improve pipe hydraulic capacity), (2) replacement with the same diameter; (3) replacement with larger diameter and (4) do nothing (Kleiner et al., 2001). Rajani et al., (2004) addressed the effect of various cathodic protection measures on life-cycle costs of water mains. Water mains can be rehabilitated using one of the trenchless methods or open-cut (Najafi et al., 2004). The national guide to sustainable municipal infrastructure has performed a series of best practices for potable water (NGSMI, 2003 a $\& b)$. These series have covered most of the available technologies for rehabilitation of water mains. The American Water Works Association (AWWA) has published a guide that includes different rehabilitation methods. Rehabilitation of existing distribution mains with a high number of service line connections presents a complicated problem for rehabilitation alternatives (O'Day and Kelly, 1992). Rehabilitation techniques might include epoxy lining, resin impregnated fabric lining, thermoplastic pipe and slip lining (O’Day and Kelly, 1992, Engelhardt et al., 2000). Jones (1992) classified the rehabilitation techniques into structural and non-structural techniques. Rehabilitation projects of water mains are classified into three main categories (AWWS, 2002; NGSMI, 2003a\&b; AWWA, 2001; Najafi, 2005; Dillon, 2003; Heavens, 1999; O'Day and Kelly, 1992; and Engelhardt et al., 2000): (1) repair (e.g. Open trench, sleeves); (2) renovation (e.g. slip lining, cement lining, epoxy lining, CIPP); and (3) replacement (e.g. pipe bursting, micro-tunneling, directional drilling, auger boring, and open cut).

The implementation timing of new pipe and its service life, which minimizes the life cycle cost over a lifetime horizon, can be modeled based on a dynamic programming approach (Kleiner et al., 2001). Two types of deterioration were proposed, namely the deterioration in the hydraulic capacity of pipes (resulting in a reduction of the supply pressure) and the deterioration of the structural integrity (causing increased breakage rates) and a subsequent increase in maintenance cost (Kleiner et al., 2001). The application of fuzzy logic to assess failure risk of large di- 


\section{Shahata and Zayed}

ameter transmission pipelines was introduced by Rajani et al. (2004).

Despite the extensive research conducted by pervious research works, the LCC analysis of various methods of new installation or rehabilitation using trenchless technologies were not covered. In addition, uncertainties associated with some life cycle cost parameters (e.g. interest rate and costs) were not addressed in previous research. Therefore, there is a crucial need to implement stochastic LCC in order to include these uncertainties and generate informed decisions.

The objective of this research is to establish a methodology in order to predict the life cycle cost for water mains considering the uncertainty involved in determining its service life, discounted rate, and the cost of new installation or rehabilitation alternatives. Therefore, this paper aims at fulfilling the following sub-objectives for water mains:

1- Identify the available installation / rehabilitation methods.

2- Design a stochastic life cycle cost (SLCC) model to select the most appropriate new installation / rehabilitation alternatives.

\section{SUMMARY OF RESEARCH METHODOLOGY}

The research methodology can be summarized in the following steps:

1- Review literature, covering all major disciplines that are necessary to evaluate the life cycle cost (LCC). It consists of problem definition, hydraulic and operating characteristics, material specification, location of connections and valves, out of service times and LCC analysis methods.

2- Collect data comprising cost information, deterioration, economic parameters and data pertaining to the available alternatives.

3- Define the SLCC profile, which consists of the main steps required to establish cost profile for each alternative.

4- Use Monte Carlo simulation to address the probability of input data.

5- Perform sensitivity analysis to examine the effect of variability of input parameters on the analysis of the overall results. This sensitivity analysis tests the variability of some uncertain input parameters by holding all other parameters constant.

6- Develop the SLCC model.

7- Generate detailed analysis report for LCC scenarios.

\section{DATA COLLECTION AND ANALYSIS}

The required data consisted of operation, maintenance, and replacement cost; deterioration rate (service life of pipe); and discounted rate. Costs were represented using triangu- lar probability distribution with minimum, most likely and maximum values. Time of breaks and type of repair data were collected from Canadian municipalities to predict the service life of water mains. Data were analyzed and probability distribution functions were used with mean $(\mu)$, and standard deviation $(\sigma)$ to model the timing of each breaks. Discounted rate data were collected from bank of Canada as a normal probability distribution function. Data collection and analysis were presented in the first companion paper; therefore, the reader is referred to the other paper for more details regarding data.

\section{STOCHASTIC LIFE CYCLE COST (SLCC) MODEL DEVELOPMENT}

The major components of SLCC procedure are summarized in Figure $1 \& 2$. It can be outlined as follows: (1) define the main problem items (i.e. scope, evaluation criteria (e.g. acceptable risk level), rehabilitation alternatives, cost elements); (2) decide the LCC approach (i.e. probabilistic vs. deterministic); (3) assign economic parameters (e.g. discounted rate, analysis period); (4) develop cash flow profile for each alternative (i.e. rehabilitation activities and their time interval based on deterioration and breakage rate analysis, estimate the rehabilitation technique cost); (5) compute Equivalent Annual Uniform Cost (EAUC) for each alternative; (6) perform analysis (i.e. sensitivity analysis, uncertainty analysis); and (7) analyze results and generate final report.

Based on the collected data, cost was estimated for several scenarios in order to establish the cash flow profile considering time of occurrence of each type of cost. The present value (PV) for each scenario is calculated. Hence, Equivalent Uniform Annual Cost (EAUC) was calculated for each scenario by substituting PV cost in Equation (1). Since the analysis period was not constant for all scenarios, the EAUC equation was used to compare various alternatives.

$$
\text { EAUC }=A_{k}+\frac{\sum_{i=0}^{n}\left[P V_{\text {Cost }_{j}}\right]}{\left(\frac{1}{(1+r)^{n}}\right)}
$$

Where, EAUC is Equivalent Uniform Annual Cost; $A_{k}$ is the annual cost for regular maintenance, $n$ is total service life of water mains; $r$ is the discounted rate; $P_{\text {Cost } j}$ is the calculated present value of costs for installation, rehabilitation, repair...etc.

Costs, service life, and discounted rate were presented as random variables with probability distributions. Therefore, EAUC could be described as a random variable as well. The alternatives used for rehabilitation project(s) are shown in Table 1. Based on these alternatives, some scenarios were suggested. Scenarios were developed in 6 main 


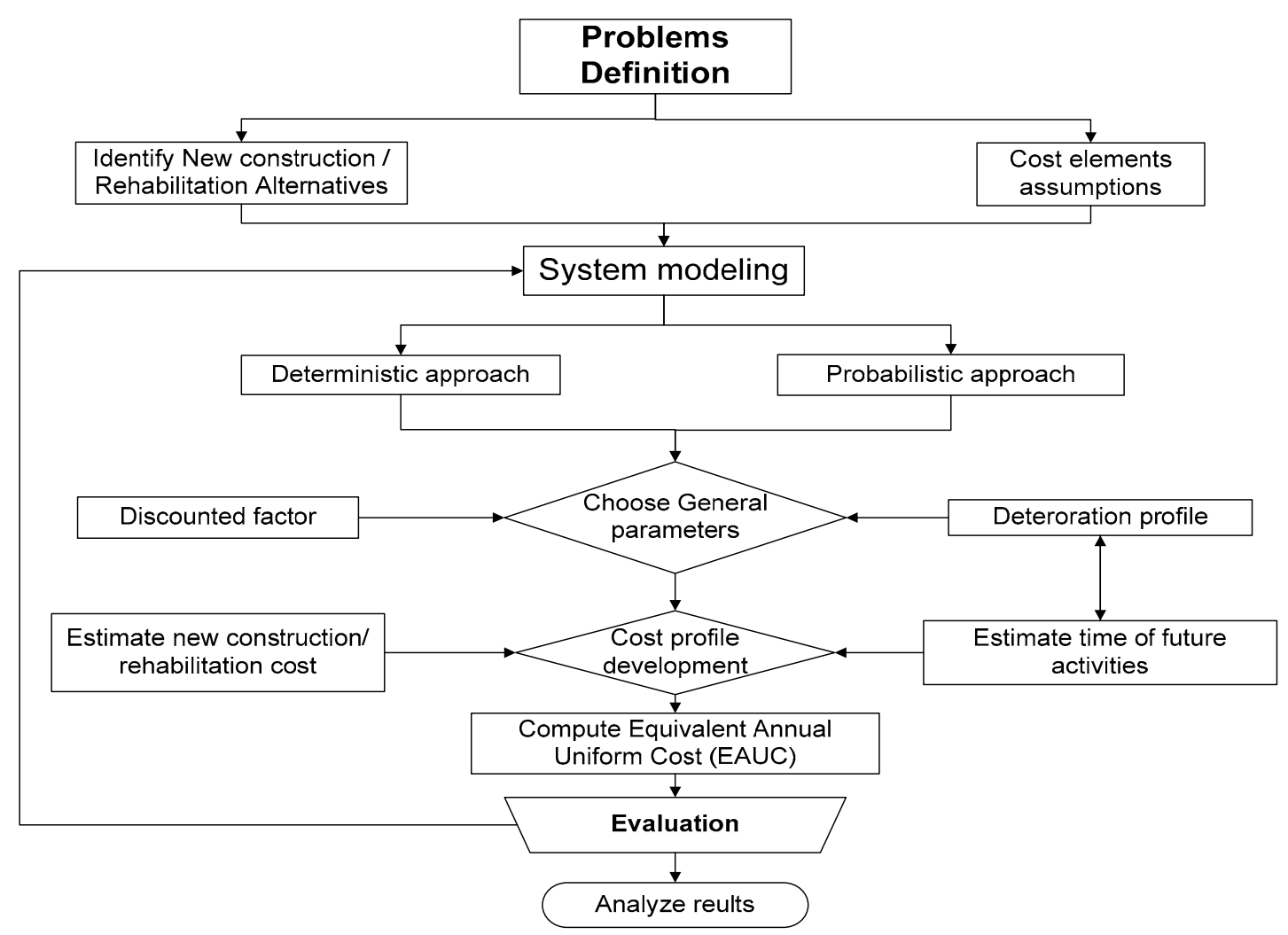

Figure 1 Life Cycle Cost Procedure

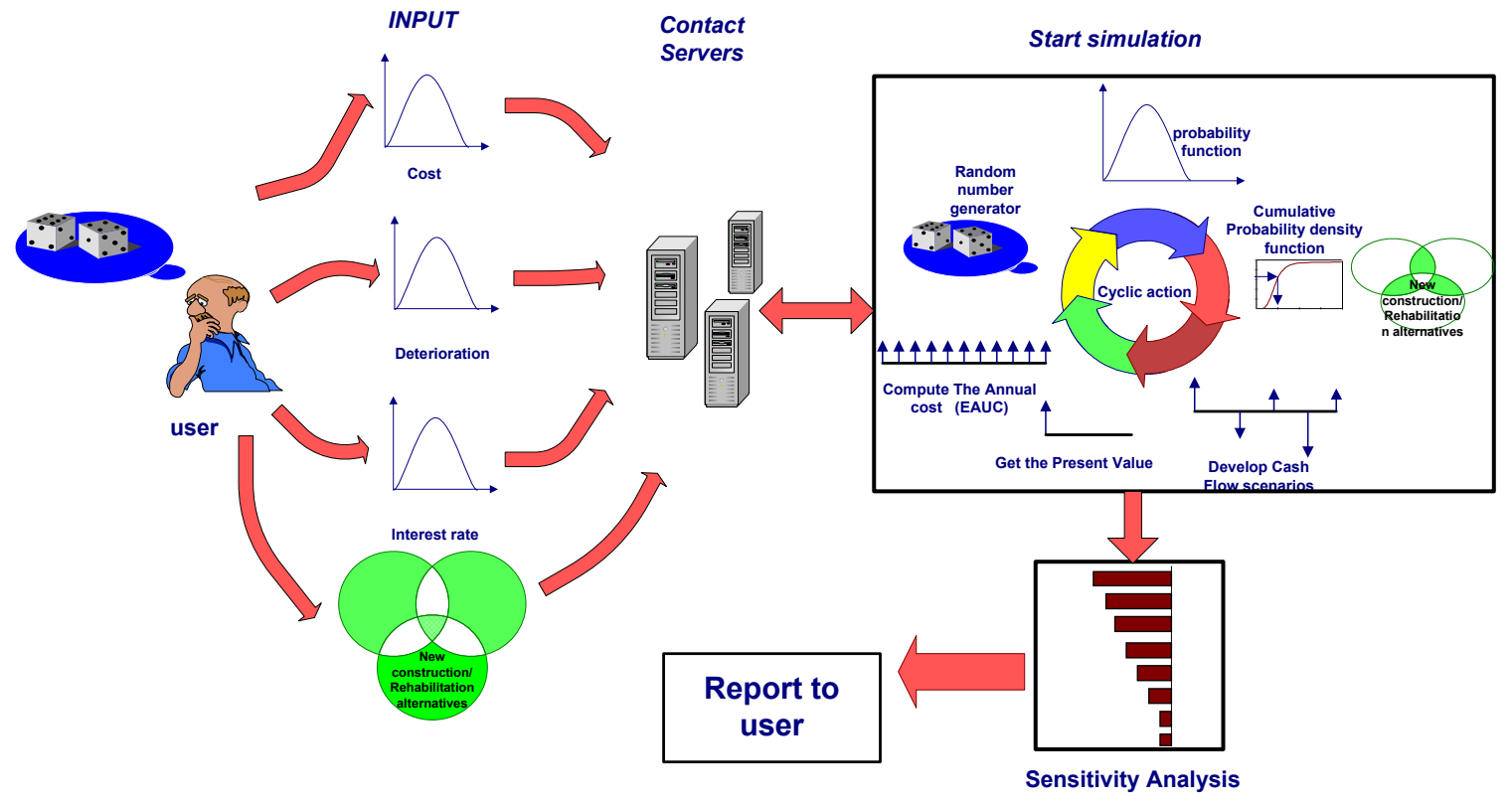

Figure 2 Stochastic Life Cycle Cost (SLCC) Model 


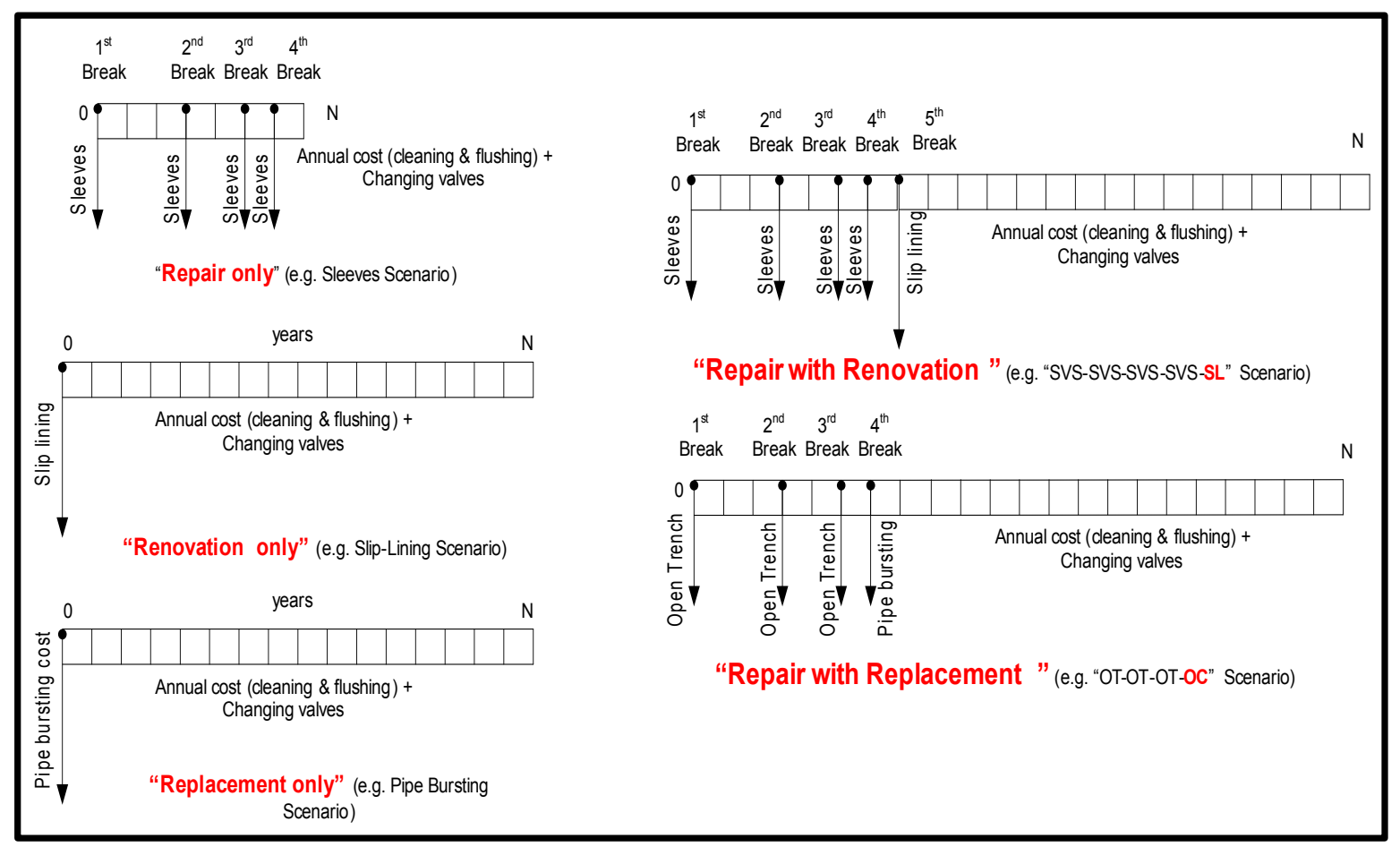

Figure 3 Examples of Suggested Scenarios

categories as shown in Table 2. The total number of the suggested scenarios was sixty scenarios. Example of cash flow for repair, renovation, and replacement scenarios are shown in Figure 3. The scenarios were developed based on water mains' service life and breaks intervals such that when a break occurs, a rehabilitation method from the available alternatives is used in which this procedure can be applied up to a maximum of five breaks.

Table 1 Rehabilitation Alternatives

\begin{tabular}{|l|l|c|}
\hline $\begin{array}{c}\text { Rehabilitation } \\
\text { Alternatives }\end{array}$ & $\begin{array}{c}\text { Rehabilitation Techniques } \\
\text { in each Alternative }\end{array}$ & Symbol \\
\hline \multirow{3}{*}{ Repair } & Sleeves & SVS \\
\cline { 2 - 3 } Renovation & Open trench & OT \\
\hline & Cement or epoxy lining & C/EL \\
\cline { 2 - 3 } & Slip lining & SL \\
\cline { 2 - 3 } & Curried in Place Pipe & CIPP \\
\hline \multirow{5}{*}{ Replacement } & Pipe Bursting & PB \\
\cline { 2 - 3 } & Open Cut & OC \\
\cline { 2 - 3 } & $\begin{array}{l}\text { Horizontal Directional } \\
\text { Drilling }\end{array}$ & HDD \\
\cline { 2 - 3 } & Micro-tunneling & MT \\
\hline
\end{tabular}

\section{SLCC IMPLEMENTATION AND ANALYSIS}

The SLCC model was applied for various types of water mains, i.e. Cast Iron, Ductile Iron, PVC, Concrete and As- bestos Cement. Due to paper size limitation, the implementation procedure only focuses on Cast Iron pipelines as an example in which the same procedure can be implemented on the rest of water main types.

The simulation procedure randomly samples the inputs and produces outputs that are described by both probability distributions and accumulative curves. The rehabilitation alternatives in Table 1 and the suggested scenarios in Table 2 were implemented on Cast Iron pipelines. The developed SLCC model was implemented in order to select the costeffective scenario. Then, sensitivity analysis was performed for each rehabilitation scenario. The results were first presented according to the utilized pipe material. This section shows an overview of the developed model results of Cast Iron with pipe diameter: 150 to $600 \mathrm{~mm}$. The LCC for the minimum twenty rehabilitation scenarios are summarized in Table 3. They show that the minimum EAUC is concluded for repair scenarios, followed by repair with renovation and finally, by repair with replacement.

The input data for the model were composed of cost (operation and maintenance cost, rehabilitation alternatives cost), deterioration rate (service life of the pipe), and discounted rate. The costs were represented in a triangular probability distribution function with minimum, most likely, and maximum costs. For both service life and discounted rate, input data were represented using normal and $\log$ normal probability distribution functions with mean $(\mu)$ and standard deviation $(\sigma)$. The scenarios are listed in abbreviation (Table 1) format where "OT-OT-OT-OT-SL" means: using open trench (OT) for four times (i.e. in the 
$1^{\text {st }}, 2^{\text {nd }}, 3^{\text {rd }}$, and $4^{\text {th }}$ breaks), then, renovate the whole pipe using slip lining (SL) after the $5^{\text {th }}$ break. Similarly, "OTOT-OT-OT-C/EL" represents open trench (OT) for the $1^{\text {st }}$, $2^{\text {nd }}, 3^{\text {rd }}$, and $4^{\text {th }}$ breaks, then, renovate the whole pipe using cement or epoxy lining (C/EL) after the $5^{\text {th }}$ break. The cumulative graph, as illustrated in Figure 4, shows that the probability of "OT-OT-OT-OT-SL" scenario has higher EAUC values than "OT-OT-OT-OT-C/EL" by $40 \%$. However, OT-OT-OT-OT-SL scenario has the lowest EAUC value. Also, Figure 4 shows a $70.5 \%$ probability that the "OT-OT-OT-OC" scenario will have larger EAUC values than "OT-OT-OT-PB" scenario.

Figure 5 shows a graph that superimposes the output data and fitted distribution for "OT-OT-OT-OT-SL" and "OT-OT-OT-OT-C/EL" scenarios, allowing for a direct visual comparison. This graph allows you to determine if the fitted distribution matches the output data in specific areas. For example, it may be important to have a good match around the mean or in the tails of the probability distribution. Figure also shows the Probability-Probability (P$\mathrm{P})$ graph that plots the distribution of the input data $(\mathrm{Pi})$ versus the distribution of the best fit function. If the fit is "good" the plot will be nearly linear. Based on the chisquared fit statistics, Log-Logistic (4107.3, 18844, 6.0164), and Lognormal (16176, 7585.1, Shift (8105.4)) best fits the output data for "OT-OT-OT-OT-SL" and "OTOT-OT-OT-C/EL" scenarios, respectively.

Figure 6 shows the sensitivity analysis of repair with renovation category for "OT-OT-OT-OT-SL" and "SVSSVS-SVS-SVS-SL" scenarios, which describes how changing inputs affect the outputs. A sensitivity coefficient value of 1 indicates a complete positive correlation between two variables. Though, a value of -1 indicates a complete inverse correlation between two variables and the value of 0 indicates that there is no correlation between variables. The sensitivity of $150-600 \mathrm{~mm}$ (6"-24") diameter range of Cast Iron water mains shows that Slip-Lining cost has the highest effect on the EUAC with a positive sensitivity coefficient ranges from 0.756 to 0.753 . The service life as well as the timing of the $1^{\text {st }}, 2^{\text {nd }}, 3^{\text {rd }}$, and $4^{\text {th }}$ breaks have significant negative sensitivity coefficient impact on the EUAC ranges from -0.379 to -0.191 . The discounted rate has significant positive sensitivity coefficient effect on EUAC (0.192). Other values of sensitivity coefficients indicate a partial correlation in which the output is affected by changes in the selected input but may be affected by other variables as well.

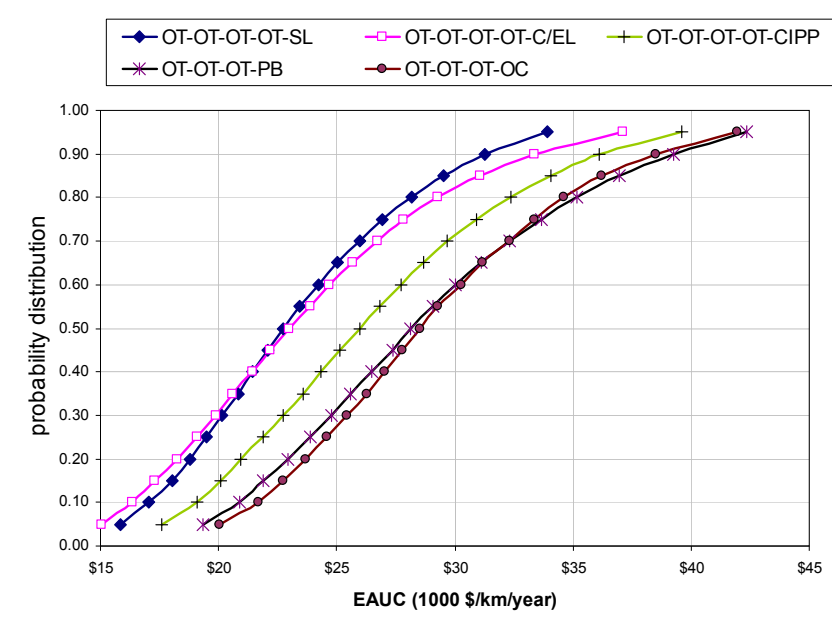

Figure 4 Cumulative Probability Distribution for Various Scenarios of Cast Iron Water Mains

Table 2 Suggested Scenarios

\begin{tabular}{|c|l|c|}
\hline Category & Operation Description & No. of Scenarios \\
\hline 1 & Repair only & 2 \\
\hline 2 & Renovation only & 3 \\
\hline 3 & Replacement only & 4 \\
\hline 4 & Repair \& renovation & 24 \\
\hline 5 & Repair \& replacement & 18 \\
\hline 6 & $\begin{array}{l}\text { Renovation \& re- } \\
\text { placement }\end{array}$ & 9 \\
\hline & Total & $\mathbf{6 0}$ \\
\hline
\end{tabular}
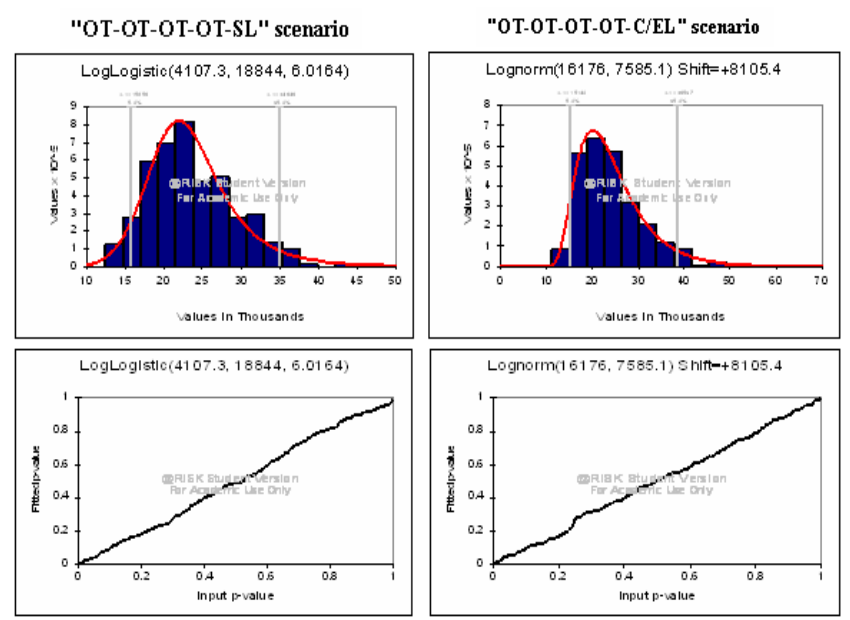

Figure 5 Comparison \& Probability-Probability (P-P) Graph for "Repair \& Renovation" Category 


\section{Shahata and Zayed}

Table 3 Top Twenty Minimum Scenarios for Cast Iron Water Mains

\begin{tabular}{|l|c|c|c|}
\hline \multirow{2}{*}{ Scenario name } & \multicolumn{3}{|c|}{ EUAC Statistics (\$/km/year) } \\
\cline { 2 - 4 } & $\begin{array}{c}5 \% \\
\text { percentile }\end{array}$ & Mean & $\begin{array}{c}95 \% \\
\text { percentile }\end{array}$ \\
\hline Open trench (OT) & $\$ 6,392$ & $\$ 7,660$ & $\$ 8,955$ \\
\hline sleeves (SVS) & $\$ 6,805$ & $\$ 8,208$ & $\$ 9,698$ \\
\hline OT-OT-OT-OT-SL & $\$ 15,873$ & $\$ 23,649$ & $\$ 33,928$ \\
\hline $\begin{array}{l}\text { SVS-SVS-SVS-SVS- } \\
\text { SL }\end{array}$ & $\$ 16,019$ & $\$ 23,830$ & $\$ 34,138$ \\
\hline OT-OT-OT-OT-C/EL & $\$ 15,074$ & $\$ 24,184$ & $\$ 37,134$ \\
\hline $\begin{array}{l}\text { SVS-SVS-SVS-SVS- } \\
\text { C/EL }\end{array}$ & $\$ 15,265$ & $\$ 24,447$ & $\$ 37,550$ \\
\hline OT-OT-OT-SL & $\$ 16,740$ & $\$ 25,405$ & $\$ 37,035$ \\
\hline SVS-SVS-SVS-SL & $\$ 16,838$ & $\$ 25,551$ & $\$ 37,228$ \\
\hline OT-OT-OT-C/EL & $\$ 16,190$ & $\$ 26,948$ & $\$ 42,973$ \\
\hline OT-OT-OT-OT-CIPP & $\$ 17,613$ & $\$ 26,957$ & $\$ 39,618$ \\
\hline $\begin{array}{l}\text { SVS-SVS-SVS-SVS- } \\
\text { CIPP }\end{array}$ & $\$ 17,817$ & $\$ 27,138$ & $\$ 39,736$ \\
\hline SVS-SVS-SVS-C/EL & $\$ 16,358$ & $\$ 27,171$ & $\$ 43,219$ \\
\hline OT-OT-SL & $\$ 17,790$ & $\$ 27,689$ & $\$ 41,111$ \\
\hline SVS-SVS-SL & $\$ 17,901$ & $\$ 27,795$ & $\$ 41,227$ \\
\hline OT-OT-OT-CIPP & $\$ 18,600$ & $\$ 29,055$ & $\$ 42,784$ \\
\hline SVS-SVS-SVS-CIPP & $\$ 18,743$ & $\$ 29,201$ & $\$ 43,113$ \\
\hline OT-OT-OT-PB & $\$ 19,355$ & $\$ 29,306$ & $\$ 42,378$ \\
\hline SVS-SVS-SVS-PB & $\$ 19,488$ & $\$ 29,451$ & $\$ 42,535$ \\
\hline OT-OT-OT-OC & $\$ 20,043$ & $\$ 29,505$ & $\$ 41,946$ \\
\hline SVS-SVS-SVS-OC & $\$ 20,190$ & $\$ 29,650$ & $\$ 42,225$ \\
\hline
\end{tabular}

\subsection{Comparison of Rehabilitation Scenarios}

This section highlights the major rehabilitation scenarios and compares the output results of various water main types. Table 4 shows a comparison matrix for the rehabilitation of various diameters of water mains. It compares the mean of EAUC values for each pipe material using the following scenarios: "OT-OT-OT-OT-SL", "OT-OT-OT-OTC/EL", "OT-OT-OT-OT-CIPP", "OT-OT-OT-OC", "OTOT-OT-PB”, “OT-OT-OT-HDD”. The reference cell is "OT-OT-OT-OT-SL" scenario, Cast Iron pipes with 150$600 \mathrm{~mm}$ (6"-24") diameter range, having a mean EAUC value of $23,649 \$ / \mathrm{km} / \mathrm{yr}$. All the other values in Table 4 are expressed as a percent of this reference scenario. This table is a good reference for these water main types, which provide a quick estimate of the expected life cycle cost for each scenario. The need for these comparison tables is necessary for decision makers at the water distribution network level. Decision makers can take the suitable decision and plan for budget allocation using the help of these kinds of tables.
Table 4 Comparison Matrixes of the Results of Rehabilitation Scenario(s)

\begin{tabular}{|c|c|c|c|c|c|}
\hline \multirow{3}{*}{ Scenario Name } & \multicolumn{5}{|c|}{ Pipe Properties } \\
\hline & Cast Iron & $\begin{array}{l}\text { Ductile } \\
\text { Iron }\end{array}$ & PVC & Concrete & $\begin{array}{c}\text { Asbestos } \\
\text { Cement }\end{array}$ \\
\hline & \multicolumn{5}{|c|}{150 to $600 \mathrm{~mm}$ (6"-24") Diameter } \\
\hline OT-OT-OT-OT-SL & $100 \%$ & $100 \%$ & $100 \%$ & $101 \%$ & $100 \%$ \\
\hline OT-OT-OT-OT-C/EL & $102 \%$ & $103 \%$ & $103 \%$ & $102 \%$ & $102 \%$ \\
\hline OT-OT-OT-OT-CIPP & $114 \%$ & $114 \%$ & $113 \%$ & $114 \%$ & $114 \%$ \\
\hline OT-OT-OT-OC & $125 \%$ & $118 \%$ & $96 \%$ & $102 \%$ & $11 \%$ \\
\hline OT-OT-OT-PB & $124 \%$ & $124 \%$ & $122 \%$ & $139 \%$ & $146 \%$ \\
\hline OT-OT-OT-HDD & $188 \%$ & $194 \%$ & $194 \%$ & $180 \%$ & $176 \%$ \\
\hline Scenario Name & \multicolumn{5}{|c|}{750 to $1000 \mathrm{~mm}(30 "-42 ")$ Diameter } \\
\hline OT-OT-OT-OT-SL & $188 \%$ & $188 \%$ & $189 \%$ & $188 \%$ & $185 \%$ \\
\hline OT-OT-OT-OT-C/EL & $202 \%$ & $202 \%$ & $202 \%$ & $203 \%$ & $201 \%$ \\
\hline OT-OT-OT-OT-CIPP & $228 \%$ & $228 \%$ & $229 \%$ & $228 \%$ & $227 \%$ \\
\hline OT-OT-OT-OC & $202 \%$ & $219 \%$ & $175 \%$ & $158 \%$ & $209 \%$ \\
\hline OT-OT-OT-PB & $261 \%$ & $243 \%$ & $265 \%$ & $215 \%$ & $250 \%$ \\
\hline OT-OT-OT-HDD & $445 \%$ & $417 \%$ & $418 \%$ & $351 \%$ & $417 \%$ \\
\hline Scenario Name & \multicolumn{5}{|c|}{$1000 \mathrm{~mm}$ and above (42"-above) Diameter } \\
\hline OT-OT-OT-OT-SL & $267 \%$ & $270 \%$ & $271 \%$ & $270 \%$ & $268 \%$ \\
\hline OT-OT-OT-OT-C/EL & $281 \%$ & $281 \%$ & $281 \%$ & $283 \%$ & $284 \%$ \\
\hline OT-OT-OT-OT-CIPP & $330 \%$ & $330 \%$ & $331 \%$ & $330 \%$ & $330 \%$ \\
\hline OT-OT-OT-OC & $256 \%$ & $261 \%$ & $226 \%$ & $175 \%$ & $260 \%$ \\
\hline OT-OT-OT-PB & $421 \%$ & $413 \%$ & $382 \%$ & $314 \%$ & $412 \%$ \\
\hline OT-OT-OT-HDD & $806 \%$ & $737 \%$ & $740 \%$ & $624 \%$ & $735 \%$ \\
\hline
\end{tabular}

\section{CONCLUSIONS}

A stochastic model has been developed to perform SLCC analysis for several water main rehabilitation alternatives. A maintenance plan was developed for water main rehabilitation alternatives based on the SLCC model. Web-based SLCC (WSLCC) software was developed to perform the SLCC of water mains. The web-based software saves significant time and money in performing the cost analysis of water mains. The system will help municipal engineers to predict the suitable new installation and/or rehabilitation programs as well as their corresponding costs, thereby to avoid any unpleasant surprises. A combination of repair, renovation, and replacement techniques are integrated in the model to develop different scenarios for rehabilitation of water mains. Output results of the SLCC model, with 95\% confidence level, showed that: Open Trench is the most appropriate for all diameter ranges within the "repair only" scenarios. Slip-Lining is the cost effective technique for all diameter ranges within the "renovation only" scenarios. Pipe bursting is the cost effective technique for small diameters 150 to $600 \mathrm{~mm}$ (6" to 24 ") within the "replacement only" scenario, while Open Cut is the cost effective 


\section{Shahata and Zayed}

technique for large diameters $750 \mathrm{~mm}(>30$ ") in the "replacement only" scenarios.

Further analysis has shown that "OT-OT-OT-OT-SL" scenario is the cost effective scenario within "repair \& renovation" category for all selected diameter ranges. Both "OT-OT-OT-PB" and "OT-OT-OT-OC" have relatively similar EAUC for small diameter ranges within "repair \& replacement" category. As water main diameter increases, "OT-OT-OT-OC" scenario yields a lower EAUC than "OT-OT-OT-OT-SL" scenario. Using "OT-SL", "OT-OTSL", or "OT-OT-OT-SL" provides a higher EAUC than "OT-OT-OT-OT-SL” for all diameter ranges.

\section{REFERENCES}

American Water Works Association (AWWA) Manual of Water Supply Practices, 2001. "Rehabilitation of Water Mains", (M 28) second edition June, ISBN: 1583210261

Arditi, D., and Messiha, H. M., 1999. "Life cycle cost analysis (LCCA) in municipal organizations.' Journal of Infrastructure Systems, ASCE, 5(1), pp. 1-10.

Dillon Consulting Limited and harfan Technologies Inc., 2003. "City of Moncton Water main Transmission and Distribution System Needs Assessment Study"; Moncton, New Brunswick, Report no. 02-0904-0700 July

Engelhardt, M. O., Skipworth, P. J., Savic, D. A., Saul, A. J., Walters., G. A., 2000. "Rehabilitation strategies for water distribution networks: a literature review with a UK perspective", Urban Water, v 2, n 2, June, pp. 153-170

Frangopol, D. M., Kong, J. S., and Gharaibeh, E. S., 2001. "Reliability based life-cycle management of highway bridges." J. of Computing in Civil Eng., ASCE, 15(1): pp. $27-34$

Gransberg, D. and Diekmann, J., 2004. "Quantifying pavement life cycle cost inflation uncertainty," Transactions, AACE, International, Washington, DC, June, pp. R.08.01-R.08.11

Hass, R., Hudson, W., and Zaniewski, A., 1994. "Modern pavement management" Krieger Publishing, Malabar, Florida.

Heavens, J. W., 1999. "Rehabilitation of water mains by trenchless renovation," Proceedings of the Group of ASCE Technical Sessions at the 1999 American Public Works Assoc. Int. Public Works Congress \& Exposition, Denver, Colorado, September 19-22, pp. 160170 .

Hudson, W., Hass, R., and Uddin, W. 1997. "Infrastructure management," McGraw-Hill, New York.

Jones, M.P., 1992. "Review of current UK techniques for rehabilitating water mains," Water Resources Planning and Management: Saving a Threatened Resource
- In Search of Solutions, Proceedings of the Water Resources Sessions at Water Forum, Page: 764

Kahraman, C., Ruan, D., and Tolga, E., 2002. "Capital budgeting techniques using discounted fuzzy versus probabilistic cash flows" Information Science, Elsevier Science Inc., May, 142(1), pp. 57-76.

Kleiner, Y., Adams, B. J., and Rogers, J. S., 2001. "Water Distribution Network Renewal Planning," Journal of Computing in Civil Engineering, ASCE, January, $15(1)$, pp. 15-26.

Najafi, M. and Kim, K.O., 2004. "Life-Cycle-Cost Comparison of Trenchless and Conventional Open-Cut Pipeline Construction Projects," Proceedings of the ASCE Pipeline Division Specialty Congress - Pipeline Engineering and Construction, San Diego, California, August 1-4, pp. 635-640

Najafi, M., 2005. "Trenchless Technology, pipeline and utility design, construction, and renewal," McGrawHill, (C2005, New York, ISBN: 0071422668

National Guide to Sustainable Municipal Infrastructure (NGSMI), 2003a. "Selection of Technologies for the Rehabilitation or Replacement of Sections of a Water Distribution System" InfraGuide, Issue No 1.0, March, Ottawa, Ontario

National Guide to Sustainable Municipal Infrastructure (NGSMI), 2003b. "Developing a Water Distribution System Renewal Plan” InfraGuide, Issue No 1.0, November, Ottawa, Ontario

National Research Council (NRC), 2004. "Assessing Canada's Infrastructure Needs: A Review of Key Studies" Infrastructure Canada research report, Ottawa, Ontario, September.

O'Day, D. K., 1992. " Water main rehabilitation needs for the 1990's," Water Resources Planning and Management: Saving a Threatened Resource - In Search of Solutions, Proceedings of the Water Resources Sessions at Water Forum, pp. 760

Rajani, B. and Kleiner, Y., 2004. "Alternative strategies for pipeline maintenance/renewal "AWWA 2004 Annual Conference, Orlando, Florida, June 13-17, pp. 1-16

Salem, O., AbouRizk, S., and Ariaratnam, S., 2003. "Riskbased life-cycle costing of infrastructure rehabilitation and construction alternatives." J. Infrastructure Systems, ASCE, 9(1), pp. 6-15.

Shahata, K., 2006. "Stochastic life cycle cost modeling approach for water mains," M.A.Sc. Thesis, Concordia University, Montreal, QC, Canada

Shahata, k., Zayed, T., and Al-Jibouri, S., 2006. "Rehabilitation scenarios for sustainable water mains," Proceedings of the 2006 Pipeline Division Specialty Conference - Pipelines 2006, ASCE, July 30-August 2, 2006, Chicago, Illinois, USA. 